given relating to water works. These omissions show the defects of the author's system of classification, and demonstrate how impossible it is to write a satisfactory one-volume treatise on civil engineering at the present day. A comprehensive treatise, like the Handbuch der Ingenieurwissenschaften, must consist of many volumes and be the work of many men.

Mansfield Merriman.

Lehigh University, July 29, 1895.

\section{Electricity Up to Date for Light, Power and} Traction. JoHn B. Verity. London and New York, Frederick Warne \& Co. 1894.

The preface of this book tells us that 15,000 copies have found their way into circulation. The title is a misnomer, unless the date is mentioned. In these days of active investigation and rapid application of discovered principles a book on electricity is out of date as it drops from the press. This statement is exemplified in this publication. The recent lucid investigations of Mr. R. E. Crompton on electric heating do not appear, and the surprising results of Mrs. Ayrton on the electric arc receive no mention. The various prime movers are mentioned, excepting the steam turbine, which, perhaps, is the most promising of all motors. The author ignores pretty generally what America is doing in the electric field, except in the case of Edison, to whom he gives credit for what was known before Edison was born-' the subdivision of the electric light.'

One of the first and certainly one of the simpiest arc lamps, and the one most used, the Brush, receives no mention. There are several expressions which ought to be omitted from popular books, to prevent the spreading of erroneous ideas. Among these are 'Storage of Electricity,' used in this book as the head of a chapter; 'Electric Pressure,' for 'Difference of Potential.'
The confounding of these terms causes great confusion in the schools. We expect better things in a book which professes to be both scientific and popular. On page 184 is the statement that in a wire through which a current of electricity is passing 'the heat generated is proportional to the quantity of current used;' it would have been just as easy to have stated the exact law. The book is well printed and illustrated, but it is difficult to treat so large a subject in 200 pages with success. J. W. Moore.

Lafayette College.

Neudrucke von Schriften und Karten über Meteorologie und Erdmagnetismus herausgegeben von Professor Dr. G. Hellmann, No. 4. E. Halley, W. Whiston, J. C. Wilcke, A. von Humboldt, C. Hansteen. Die ältesten Karten der Isogonen, Isoklinen, Isodynamen; 1701, 1721, 1768, 1804, 1825, 1826. Berlin, A. Ascher \& Co. 1895. Sieben Karten in Lichtdruck mit einer Einleitung. 26 pp., 4 to.

The above forms No. 4 of the very interesting series of reprints in facsimile of epochmaking rare old books or charts in Meteorology and Terrestrial Magnetism edited by the well-known meteorologist and bibliographer, Professor Hellmann, of Berlin.

Like its predecessors, $*$ the number before us commends itself by its keen, critical and thorough research, by its beautiful typographical execution and by the lowness of the price. Hardly one of the seven charts given could be obtained for the price ( 5 marks) asked for the whole. It is needless to remark that the editor of these successful reprints and his coöperators, the German Meteorological Society and its Berlin Branch, have thus merited the warmest

\footnotetext{
* No. 1. L. Reynman: Wetterbüchlein. Von wahrer Erkenntniss des Wetters. 1510.

No. 2. Blaise Pascal: Récit de la Grande Expérience de l'Equilibre des Liqueurs. Paris, 1648.

No. 3. Luke Howard: On the modifications of clouds. London, 1803.
} 
praise. The pure geomagnetician will find additional satisfaction in the fact that Professor Hellmann appears to have abandoned his original intention of publishing the earliest meteorological and magnetic charts in one and the same volume. This differentiation of purely meteorological and magnetic matter cannot be too highly commended.

As announced in the title, the purpose of this number is to reproduce in facsimile the earliest geomagnetic charts. The amount of careful and painstaking research, as evinced by the many copious notes following the text, necessary for the completion of this task can only be thoroughly appreciated by those who have made similar attempts.

Plate I, gives Halley's famous lines of equal variation or magnetic declination for the epoch 1700.

Plate II, the earliest (1721) lines of equal magnetic inclination by $\mathrm{W}$. Whiston for southern England and the Channel.

Plate III, the earliest general chart of the lines of equal inclination by J. C. Wilcke, published in 1768.

Plate IV, Humboldt's attempt at a representation of the distribution of the intensity of the earth's magnetism on both sides of the equator passing through Peru.

Plate $V$, the earliest delineation of the lines of equal magnetic force by Hansteen, published in 1825 and 1826 .

A limited number of copies of the above can be obtained from the reviewer at the price named.

L. A. Bauer.

UnIVERStTy of Chicago.

\section{SCIENTIFIC JOURNALS}

THE PHYSICAL REVIEW, VOL. III., NO. 1, JULY-AUGUST.

Thermal Conductivity of Copper. By R. W. Quick, C. D. Child and B. S. Lanphear. In a former paper (Phys. Rev., Vol. II., No. 6) the writers have given an account of experiments made to determine the conductivity of copper at temperatures ranging from $70^{\circ}$ to $170^{\circ}$. The present article is devoted to experiments upon the same copper bar at temperatures below $0^{\circ}$, the results being, so far as the writer is aware, the first that have been obtained for this range of temperatures. Several modifications in the method employed were made necessary by the new conditions. As a cooling bath, in which one end of the test bar was immersed, a mixture of solid $\mathrm{CO}_{2}$ and ether was used. The temperature obtained by this means was about $-70^{\circ}$. The formation of frost on the surface of the cold bar was a source of some annoyance, but was finally prevented by placing the bar in a large box filled with dry air. The temperature of the bar was measured, as in the previous experiments, by the resistance of a coil of fine copper wire, whose temperature coefficient was determined by reference to the melting points of ice and mercury.

The results show a variation in conductivity from 0.921 at $-54^{\circ}$ to 1.059 at $13^{\circ}$. It is to be observed that the increase of conductivity with rise of temperature corresponds with the behavior of the bar at high temperatures. The increase is, however, more rapid for temperatures below $0^{\circ}$. On the other hand, the average value of the conductivity for the range $-54^{\circ}$ to $-13^{\circ}$ is found to be slightly greater than the average value between $70^{\circ}$ and $170^{\circ}$. Either, therefore, the results have been affected by some undiscovered source of error, or else the curve of conductivity must possess a maximum at some temperature between $-14^{\circ}$ and $+70^{\circ}$. Determinations of conductivity, for temperatures lying between this range are to be desired.

On Ternary Mixtures. I. By W. D. BANCROFT.

The attention which in recent years has been devoted to the subject of dissociation, 